\title{
Chiari malformation and syringomyelia
}

\author{
JNSPG 75th Anniversary Invited Review Article \\ Langston T. Holly, MD, and Ulrich Batzdorf, MD \\ Department of Neurosurgery, David Geffen UCLA School of Medicine, Los Angeles, California
}

Chiari malformation was first described over a century ago, and consists of posterior fossa anomalies that generally share the feature of cerebellar tonsillar descent through the foramen magnum. Our understanding of this disorder was initially based on autopsy studies, and has been greatly enhanced by the advent of MRI. The surgical management of Chiari anomalies has also evolved in a parallel fashion. Although the exact surgical technique varies among individual surgeons, the goals of surgery remain constant and consist of relieving brainstem compression and cranial nerve distortion, restoring the normal flow of CSF across the foramen magnum, and reducing the size of any associated syrinx cavity. Syrinx cavities are most commonly associated with Chiari anomalies, yet primary spinal syringomyelia (PSS) can be caused by traumatic, infectious, degenerative, and other etiologies that cause at least a partial CSF flow obstruction in the spinal subarachnoid space. As with syringomyelia associated with Chiari anomalies, the main goal of PSS surgery is to reestablish CSF flow across the area of obstruction. In addition to MRI, myelography with CT can be very helpful in the evaluation and management of these patients by identifying focal regions of CSF obstruction that may be amenable to surgical intervention. Future directions for the treatment of Chiari anomalies and syringomyelia include the application of advanced imaging techniques, more widespread use of genetic evaluation, large-scale outcome studies, and the further refinement of surgical technique.

https://thejns.org/doi/abs/10.3171/2019.7.SPINE181139

KEYWORDS Chiari malformation; anomaly; syrinx; syringomyelia; spinal cord; CSF; cervical

$\mathrm{T}$ HE designation "Chiari malformation" is used as shorthand for a variety of anatomical anomalies, which, with one exception, have the common feature of cerebellar tonsillar descent through the foramen magnum. In this respect, these anomalies agree with the cases described in 1891 and 1896 by Hans Chiari, ${ }^{21}$ although it is widely recognized that his autopsy studies were based on hydrocephalic infants who died soon after birth. The Scottish anatomist John Cleland ${ }^{23}$ had described a similar abnormality in 1883. Arnold's name, rarely associated with this condition in the current literature, was added by Gredig and Schwalbe, based on a somewhat similar case of cerebellar descent, but without hydrocephalus. ${ }^{63}$

It is worth noting that Chiari's type III and IV abnormalities, with displacement of the entire cerebellum out of the skull, are more correctly termed "malformations."
Type II, by definition associated with spina bifida and myelomeningocele, is thus also related to a congenital malformation. By far the most common Chiari abnormality, encountered in children and adults, is the so-called Chiari malformation type I, and critical consideration of this terminology raises the question of whether the condition represents variations of structure that allow the cerebellar tonsils to project through the foramen magnum. In some instances, the anatomical variants allow the distal brainstem, as well as the tonsils, to project through the foramen magnum. The clinical differentiation of this variant has given rise to the designation of Chiari type 1.5 (Fig. 1) ${ }^{71}$ The exception to the generalization of tonsillar descent through the foramen magnum is represented by the socalled "Chiari type 0," a condition in which some manifestations of the typical Chiari anomaly, notably syringomy-

ABBREVIATIONS HCTD = hereditary connective tissue disorder; PSS = primary spinal syringomyelia.

SUBMITTED July 7, 2019. ACCEPTED July 25, 2019.

INCLUDE WHEN CITING DOI: 10.3171/2019.7.SPINE181139. 


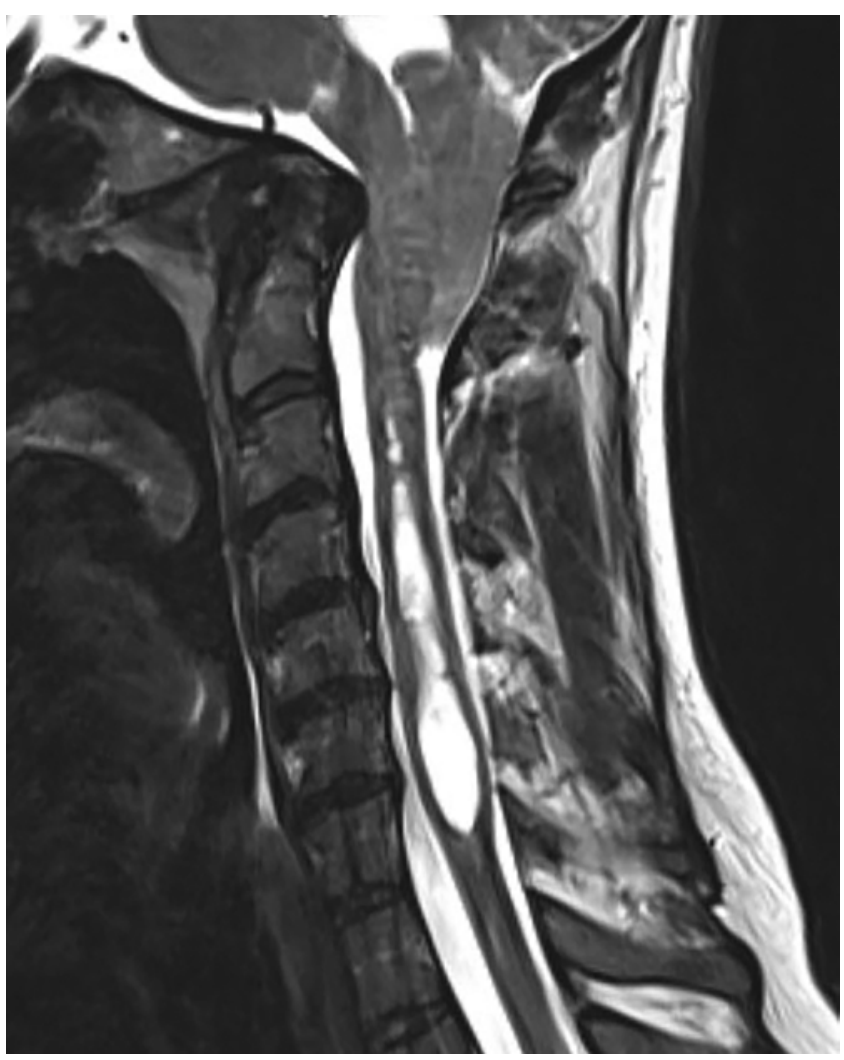

FIG. 1. Sagittal T2-weighted MR image of a 32-year-old woman with Chiari type 1.5 anomaly who presented with severe headaches, spastic quadriparesis, and significant bulbar dysfunction.

elia, result from a process of cranial CSF flow impairment at the craniocervical junction other than tonsillar descent, such as membrane formation..$^{70}$ The justification for using the term "Chiari" is that surgical treatment for these patients is similar to that used for Chiari type I abnormalities.

Recognizing that structural anatomical variants associated with a disproportion of posterior fossa volume and its contents allow the cerebellar tonsils to project through the foramen magnum, this review will use the term "Chiari anomaly" in preference to malformation.

\section{Chiari Incidence}

Although the number of patients with the imaging diagnosis of Chiari anomaly has increased greatly since the availability of MRI, the true incidence of clinically significant Chiari anomalies is considerably lower. This is the result of varying criteria used by radiologists to make a diagnosis of Chiari anomaly, as well as the problem of estimating the prevalence of Chiari anomaly on the select group of individuals undergoing imaging. The prevalence has been cited as $0.24 \%-3.6 \%$ of the population, ${ }^{43}$ and $0.56 \%-0.77 \%$ based on MRI studies. ${ }^{6,53}$ The true incidence of the structural abnormalities forming the diagnostic criteria of Chiari anomaly in the population is presumably much higher because there undoubtedly are many individuals who remain asymptomatic, even though they have structural abnormalities typical of the Chiari anomaly. Incidence figures based on pediatric populations tend to give higher prevalence figures because of the natural tendency of the tonsils to ascend with age. ${ }^{66}$ Numerous studies have demonstrated a higher prevalence among females ${ }^{68}$ It is interesting to speculate what might precipitate clinically significant symptoms in some patients who must be presumed to have had the underlying structural changes. Trauma has been identified as one possible factor. ${ }^{58}$

From a clinician's viewpoint, patients with Chiari anomalies present most frequently at two time periods: in early childhood ( 8 and 9 years) and in adults, with peak ages between 41 and 46 years. ${ }^{6}$ The reasons for these incidence peaks are not understood at the present time. There are, however, differences in treatment and treatment outcomes that apply to patients treated in early childhood and adult patients.

\section{Structural Abnormalities Constituting the Chiari Anomaly, and Genetic Relationships}

A posterior fossa that is small in relation to the size of the cerebellum is widely accepted as underlying the descent of the cerebellar tonsils through the foramen magnum, although these differences may not apply to all children. ${ }^{64}$ A relatively small posterior fossa may be the result of different factors, including low insertion of the tentorium and a more horizontally or even tipped-up occipital bone. ${ }^{10}$ Thickened calvarial bone is also capable of reducing posterior fossa volume (Fig. 2).22,62 Changes collectively termed "basilar invagination" may encroach on the posterior fossa space anteriorly. The genetic basis underlying these variants is, without doubt, not the same. Regions of linkage to Chiari anomalies have been identified on chromosomes 9 and 15, but much of this work has been conducted in conjunction with studies linking Chiari to comorbidities. ${ }^{752}$ Familial instances of Chiari anomalies have been reported and constitute a small percentage of the Chiari population seen clinically. ${ }^{1}$

\section{Secondary Chiari Anomalies}

Tonsillar descent through the foramen magnum may occur for reasons unrelated to posterior fossa morphology, but related to spinal CSF pressure differences. This includes cranial CSF hypertension, such as that which occurs in idiopathic intracranial hypertension ${ }^{14}$ or hydrocephalus, and CSF hypotension, as occurs in spinal CSF leaks and perhaps in some instances of tethered spinal cord..$^{55}$ The clinical presentation of secondary Chiari anomalies may be very similar to that of Chiari type I anomalies, and syringomyelia may develop as a result of tonsillar descent. The identification of secondary anomalies is extremely important before treatment is instituted, because in secondary Chiari anomalies treatment should be directed at the underlying cause.

\section{Complex Chiari}

Complex Chiari anomalies are defined as occurring in patients with all or some of the following imaging findings: brainstem herniation though the foramen magnum 


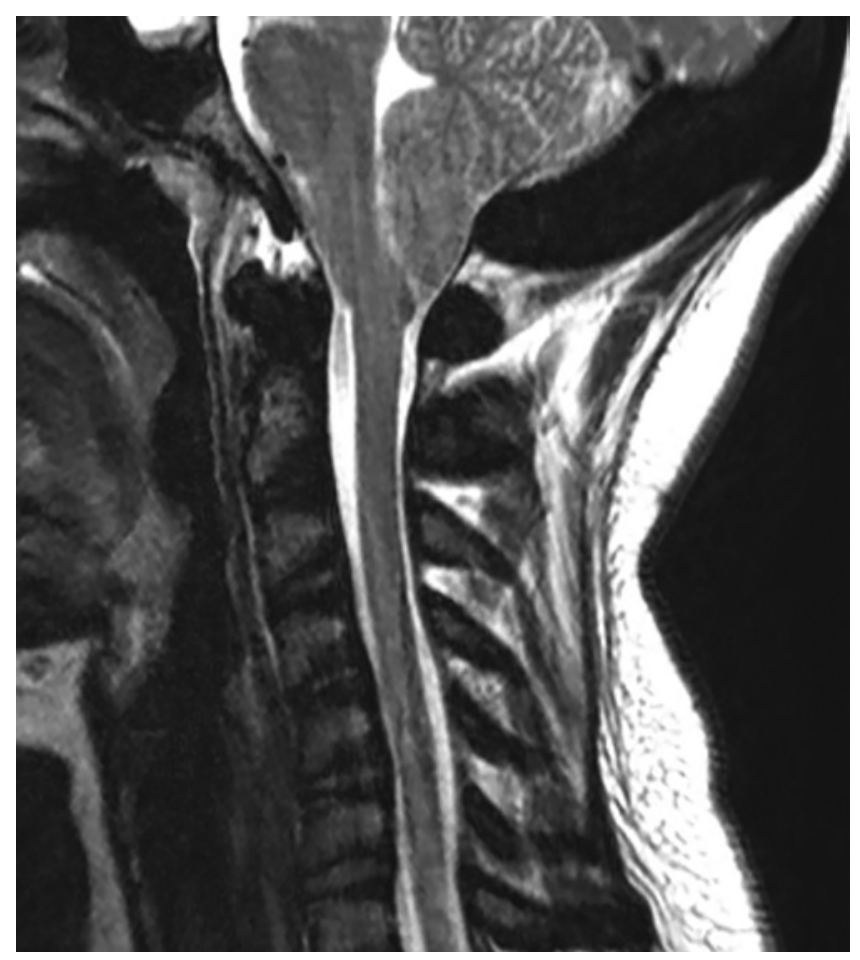

FIG. 2. Sagittal T2-weighted MR image of a 19-year-old woman with Chiari type I anomaly who presented with severe headaches and was found to have a thickened calvaria that further reduced her posterior fossa volume and contributed to her symptomatology.

(see also Chiari type 1.5), a clivoaxial angle of less than $125^{\circ},{ }_{11}$ and basilar invagination. It is generally agreed that some of these patients are more likely to require craniocervical fusion. ${ }^{18,19}$

\section{Chiari Type I as a Comorbidity}

Chiari type I anomalies may be present as a comorbidity with other entities, most notably hereditary connective tissue disorders (HCTDs) and Klippel-Feil syndrome. According to one study, $13 \%$ of 3000 Chiari patients had some form of HCTD. ${ }^{56}$ Obliteration of the cisterna magna with tonsillar descent is also observed in some children with hydrocephalus. ${ }^{69}$ Atlantoaxial instability appears to play a role in at least some patients with Chiari anomaly. ${ }^{27,31}$

\section{Etiology of Chiari-Related Syringomyelia}

The incidence of syringomyelia in patients with Chiari anomaly has been estimated at $69 \%$ in adults and $40 \%$ in children. ${ }^{6}$ Earlier concepts of the etiology of Chiari-related syringomyelia assumed a communication of the syrinx cavity with the fourth ventricle, leading to the concept of "communicating syringomyelia." It formed the basis of Gardner's operative procedure that placed a tissue plug at the most inferior point of the fourth ventricle. ${ }^{30}$ The success of this procedure in some patients may, however, have been the result of the posterior fossa bony and intradural exposure, rather than the "obex plug" as such. Absence of a communication between the fourth ventricle and the syr- inx cavity in most cases of Chiari-related syringomyelia was demonstrated in autopsy specimens by Milhorat ${ }^{57}$ and became clearly evident with the widespread use of MRI.

A more likely explanation is that advanced by Oldfield and colleagues, ${ }^{59}$ who proposed that the pulsatile movement of the cerebellar tonsils acting on an enclosed spinal subarachnoid space drives fluid into the cord parenchyma. Stoodley's research pointed to the role of arterial pulsations in the spinal subarachnoid space as contributing to the transparenchymal propagation of CSF. ${ }^{16,67}$

\section{Slit-Like Spinal Cord Cavities}

Slit-like spinal cord cavities are commonly, yet incorrectly, referred to as syringomyelia by radiologists and other healthcare professionals, but in actuality represent a persistent central canal that is found normally in a small percentage of adults. ${ }^{39}$ In contrast to a true syrinx, the persistent central canal is almost always located in the center of the spinal cord, symmetrically round, of a narrow diameter, commonly discontinuous, and tapered at its rostral and caudal ends. The factors that promote obliteration of the central canal in the course of normal human development are not known at this time. The concept that remnants of the central canal may serve as the nidus for the development of syringomyelia was noted by Milhorat. ${ }^{57}$ Because obliteration of the central canal occurs somewhat unevenly in the earlier years of life, ${ }^{76}$ it may explain why only some patients with Chiari anomaly and only some patients with spinal cord injury develop syringomyelia. In many cases, posterior fossa decompression will result in resolution of the syrinx (Fig. 3), yet in some instances an obvious central canal may remain following syrinx resolution, further supporting the concept that the central canal can act as a nidus for syringomyelia (Fig. 4).

\section{Etiology of Primary Spinal Syringomyelia}

Primary spinal syringomyelia (PSS) is defined as syringomyelia occurring in relation to pathology entirely within the spine, rather than in relation to abnormalities at the craniocervical junction. It is a far less common cause of syringomyelia than Chiari anomaly. The identified causes of PSS include spinal trauma, arachnoid cysts of the spine, and scarring due to meningitis or subarachnoid blood. Cysts associated with intraspinal neoplasms are not generally considered true syringomyelia, although neoplasms that produce significant narrowing of the subarachnoid space may have an associated syrinx cavity. Spondylotic ridges and disc herniations may also be associated with PPS. In each of these situations there appears to be at least a partial block of CSF pulsations caused by an obstruction, resulting in a pressure differential, which favors intrusion of CSF into the cord. ${ }^{34}$ Rupture of the syrinx cavity and communication with the subarachnoid space may occur at the site of spinal cord injury. ${ }^{57}$

\section{Chiari Imaging}

The diagnosis of Chiari anomaly and syringomyelia is currently made primarily on the basis of MRI studies. Conventional studies are performed with 1.5- or 3-T MRI 


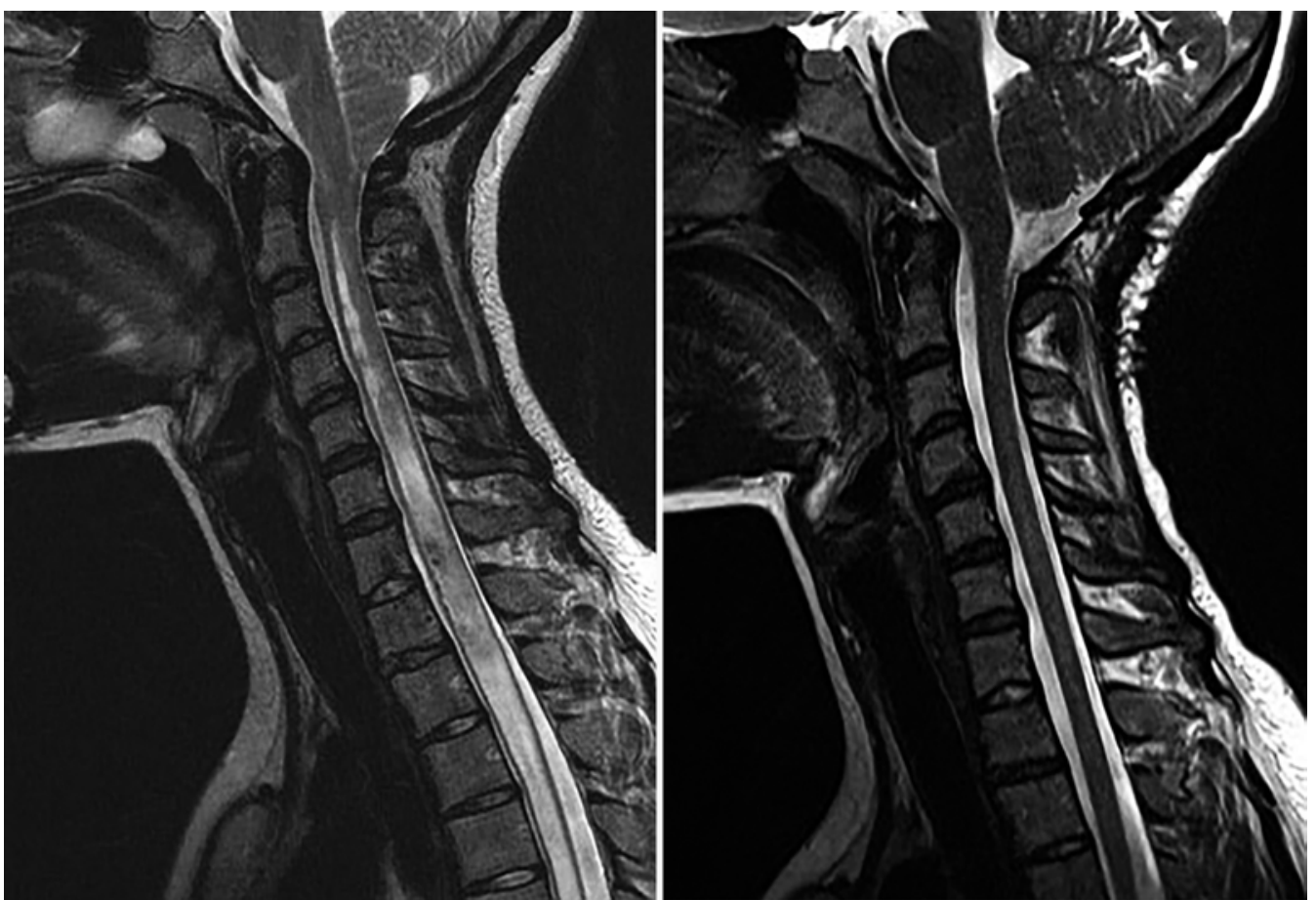

FIG. 3. Left: Preoperative sagittal T2-weighted MR image of a symptomatic 21-year-old woman with a Chiari type I anomaly and a large syrinx cavity. Right: Postoperative sagittal T2-weighted MR image following Chiari decompression surgery that demonstrates creation of a cisterna magna, rounded cerebellar tonsils, and complete resolution of the syrinx cavity.

units and with the patient supine on the examining table. In certain special situations, as in the case of patients with suspected craniocervical instability or recent trauma, there may be benefit of obtaining an upright MRI study with or without flexion and extension of the neck. Plain radiographs with flexion and extension views are helpful in cases of suspected instability.

There has been much emphasis on measurement of the extent of tonsillar descent below the foramen magnum, based on the original studies of Barkovich, who stated that patients with $5 \mathrm{~mm}$ or more of tonsillar descent were more likely to have a Chiari anomaly. ${ }^{8}$ More recently, it has become clear that the measurement of tonsillar descent does not necessarily correlate with the clinical picture. The pointed shape of the cerebellar tonsils indicative of compression, the presence or absence of CSF spaces surrounding the tonsils, and evidence of brainstem compression on axial images at the level of the foramen magnum may be as significant as a measurement of tonsillar descent. The severity of tonsillar descent also does not correlate with the presence, size, or absence of a syrinx cavity.

The value of cardiac-gated CSF flow studies of the posterior fossa is a subject of controversy, inasmuch as reduced CSF flow posterior to the tonsils is not necessarily associated with clinical symptoms. However, such studies have added considerably to our understanding of some aspects of the pathophysiology. ${ }^{48}$

\section{Imaging of PSS}

MRI is the most widely used imaging modality used to assess PSS. In posttraumatic cases and patients with arachnoid cysts or webs, myelography combined with computed axial tomography may help to identify obstructive pathology that lends itself to focal resection. Highintensity T2-weighted MRI of the spine, although not universally available, is also helpful in identifying intradural obstructive pathology. ${ }^{36}$

\section{Symptoms of Chiari Anomalies}

Symptoms of Chiari anomaly can be divided into those related to the CSF circulation and those related to compression or traction of the brainstem, cerebellar connections, and cranial nerves. Symptoms of syringomyelia are generally related to spinal cord dysfunction and related pain, as noted below. The most common symptoms related to CSF circulation are the classic tussive, or strain-related, headaches of Chiari patients, due to dural stretching as cranial volume is briefly increased and not simultaneously vented because of obstruction of CSF flow by the descended tonsils at the foramen magnum. In long-standing instances and particularly in children, this may result in hydrocephalus.

Symptoms of brainstem compression and traction on cranial nerves are noted together, as it may not be possible to distinguish the two in every patient. Patients with Chiari type 1.5 anomalies would presumably have a greater element of cranial nerve traction. Together they include nystagmus, hoarseness, speech and swallowing difficulties, and sleep apnea. ${ }^{77}$ Balance problems presumably are the result of traction or compression of cerebellar connections. Findings associated with Chiari anomaly include nystagmus, impaired gag response, and impaired limb 


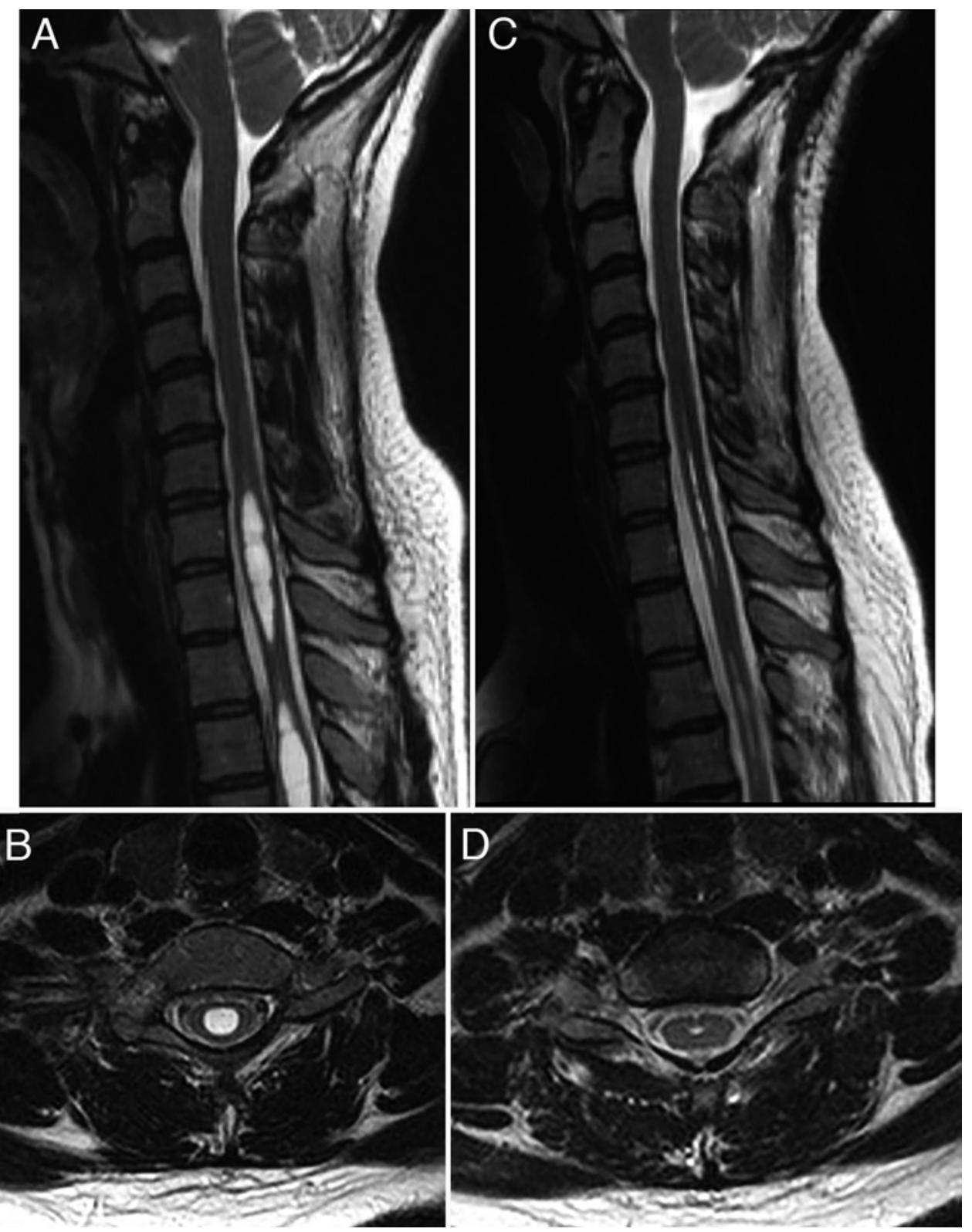

FIG. 4. A and B: Preoperative sagittal (A) and axial (B) T2-weighted MR images of a 35-year-old woman with Chiari type I anomaly and a large discontinuous syrinx cavity. $C$ and D: Postoperative sagittal (C) and axial (D) T2-weighted MR images that demonstrate satisfactory foramen magnum decompression and near-total resolution of the syrinx cavity. The features of the residual cavity are consistent with a central canal.

and gait ataxia with resulting impaired balance, as well as other less common findings. ${ }^{25}$ Syringobulbia may be encountered in patients with Chiari anomaly and may present with lower cranial nerve involvement and occasionally with diplopia.

\section{Symptoms of PSS}

Symptoms of PSS are related to the anatomical location of the cavity (cervical, thoracic, lumbar) and to the position of the cavity or cavities within the spinal cord (unilateral, bilateral, central, diffuse). The latter determine the neurological deficit associated with the syrinx cavity, which can range from minimal to complete paralysis associated with spasticity. Pain, often neuropathic in quality, is frequently associated with syringomyelia and may pose treatment challenges. In addition to medications, spinal cord stimulation has been used for treatment of these patients. Gowers is credited with first describing the so-called dissociated sensory loss, with preservation of tactile sensation and loss of pain and temperature sensation, often in cape-like distribution. ${ }^{32}$ Findings associated with syringomyelia are those typical of spinal cord dysfunction and include hand and arm weakness and hand atrophy, gait spasticity, and classic dissociated sensory im- 
pairment, particularly of the shoulder region, with loss of pain and temperature sensation, while vibratory and proprioceptive sensation remain intact.

\section{Surgery and Indications}

Surgical treatment of Chiari anomalies dates back to Penfield and Coburn, who performed a posterior fossa decompression in 1938, unfortunately with a fatal outcome. ${ }^{61}$ A major advance was made by Gardner and Angel in 1957, who performed a posterior fossa decompression and placed a tissue or cotton plug at the inferior apex of the fourth ventricle to occlude the presumed communication of the fourth ventricle with a coexisting syrinx cavity. ${ }^{30}$ As noted in the section on etiology above, the exposure as such, rather than the obex plug, may explain some of the good outcomes of his patients. The decompression procedure evolved over the years with many variations, as noted below. ${ }^{26,54}$ It is widely accepted that decompression of the posterior fossa and foramen magnum helps with respect to relief of symptoms and resolution of syringomyelia. ${ }^{6}$ There are, however, many modifications of the exact technique used.

The goals of surgical decompression should be to relieve brainstem compression and cranial nerve distortion, to restore the instantaneous venting capability of the cranial CSF compartment, and to reduce the syrinx cavity when one is present. Enlarging the cisterna magna is based on the premise that CSF pulsations in an enlarged cisterna magna will promote ascent of the cerebellar tonsils as well as aid in the propagation of CSF pulsations into the spinal subarachnoid space. ${ }^{24}$ Some, including us, believe that reducing the size of the cerebellar tonsils contributes to the enlargement of the cisterna magna and initiates ascent of the tonsils. ${ }^{13}$ Duraplasty may affect intracranial compliance $^{5}$ and appears to be associated with a lower risk of reoperation. ${ }^{54}$

\section{Children Versus Adults}

There are several reasons why the indications for Chiari surgery differ somewhat for children and adults. Predominance and progression of clinical symptoms, presence of syringomyelia, and presence of scoliosis all are important and relevant considerations. Scoliosis was the presenting symptom in $18 \%$ of a large pediatric series. ${ }^{69}$ An incidental finding of tonsillar descent, however, must be treated with caution, particularly in view of the known stability of tonsil position, and even ascent of the tonsils in some children. ${ }^{50}$ Indications for surgery must be based on clinical assessment as well as imaging. The natural history of Chiari anomaly is such that patients with clinical manifestations of marginal or doubtful significance can be observed..$^{50,68}$ Imaging studies can be repeated after an appropriate time interval, and progressive enlargement of a syrinx cavity, particularly when associated with clinical symptoms, may be an indication for surgical intervention. The rare spontaneous resolution of Chiari anomaly and syringomyelia has also been reported. ${ }^{46}$

It has been established that decompression of the posterior fossa in children lends itself to less formidable procedures than in many adults. The reasons for this are not entirely clear and different physical properties of a child's tissues, including the dura and the neural tissue itself, may play a role. Reports have shown that suboccipital bone removal alone may suffice in some children, ${ }^{42}$ while others may respond to thinning ${ }^{41}$ or scoring of the dura. ${ }^{29}$ Reoperation rates in children are not insignificant and may, in part, relate to the fact that a procedure that does not include intradural inspection will miss some relevant pathology. ${ }^{6,44}$

\section{Adult Chiari Surgery}

Some adults appear to respond to similar more minimal decompressive procedures as do children, ${ }^{28}$ but the analysis of reports is often difficult because the indications, including the type and degree of anatomical abnormality, are not always clearly comparable to those of individuals undergoing more extensive intradural procedures. Spontaneous resolution of Chiari anomaly and syringomyelia is rare but has been reported. The mechanism by which this phenomenon takes place is not clearly understood. ${ }^{46}$ The most widely practiced surgical approach today includes removal of enough occipital bone to uncover the cerebellar tonsils, a laminectomy of the first cervical vertebra, intradural inspection to identify occlusive membranes, manipulation of the tonsils with or without reduction of the tonsils, and duraplasty. The size of the craniectomy opening varies among surgeons. In our practice, it is based on measurements taken from the patient's imaging studies and usually measures $2.0-2.5 \mathrm{~cm}$ in width and $1.5-2.0$ $\mathrm{cm}$ in vertical distance from the foramen magnum. Larger openings run the risk of developing descent of the cerebellar hemispheres into the decompression and, occasionally, stretching of a dural graft..$^{24,38,73} \mathrm{~A} \mathrm{C1}$ laminectomy is performed and the atlantooccipital membrane is resected; the C2 lamina is generally left intact.

Intraoperative ultrasonography has proven particularly helpful in cases in which, for some reason, a more limited procedure is planned. ${ }^{15}$ The dura is opened: we prefer a Y-shaped opening to optimize expansion of the cisterna magna, created at the end of the procedure. The dura is retracted with sutures and the arachnoid is initially left intact, to minimize contamination of the subarachnoid space with blood. The arachnoid is then opened and adhesions around the tonsils are lysed so that the tonsils can be mobilized. Care is taken to visualize and protect the posterior inferior cerebellar arteries, which vary widely in their anatomical relationship to the tonsils. Tonsil reduction is not universally performed. In most patients, it has been our practice to use bipolar coagulation of the pial surface of the tonsil tips and medial tonsils, thereby facilitating egress of CSF from the fourth ventricle. ${ }^{13,45}$ It is not uncommon for one of the tonsils to be dominant and the primary cause of the foramen magnum obstruction. We are generally able to visualize the outlet of the fourth ventricle. Rarely, subpial resection of the tonsils is necessary, but may be required in some Chiari type 1.5 cases or other circumstances of voluminous tonsils that do not respond adequately to bipolar electrocautery. Many surgeons prefer to leave the arachnoid intact and do not reduce the cerebellar tonsils. The risk of CSF leakage does not appear to be significantly different, ${ }^{45}$ and not opening the arachnoid runs the risk of 
leaving significant intradural pathology and may result in suboptimal outcomes and the need for reoperation. Reduction in the syrinx cavity appears to be better in patients undergoing posterior fossa decompression with duraplasty, than in patients undergoing bone decompression only. ${ }^{20}$ The material used for duraplasty also varies widely and includes allograft, autologous tissue, and synthetic material. Our own practice is to use a combination of nonstretchable synthetic material together with autologous pericranium. ${ }^{13}$ Occipitocervical fusion may be indicated in patients with craniocervical instability. ${ }^{19}$

The most common complication is leakage of CSF from the incision and ranges from $4.7 \%$ to $9.6 \%{ }^{6,46}$ Contained leakage in the form of pseudomeningocele often is not regarded as a complication, although evidence has shown that such pseudomeningocele may act as a compliance reservoir and thereby impair resolution of a syrinx cavity. ${ }^{60}$ These complications can be minimized by careful attention to durotomy closure. Other complications are related to the size of the bone decompression, which may be too large or too small, and to delayed instability. An excessively large bone decompression may lead to slumping or ptosis of the cerebellum into the decompression, sometimes recreating partial obstruction to the circulation of CSF. ${ }^{24,38,73}$ Removal of the C2 lamina may risk the development of instability in some patients. ${ }^{44}$

\section{Outcomes of Chiari Surgery}

Klekamp et al. reported an overall improvement rate of $82.5 \%-84.5 \%$, related to the severity of arachnoid pathology. ${ }^{45}$ Of the numerous and varied preoperative symptoms, tussive headaches are generally reported to be the most likely to improve. ${ }^{6,25,58}$ Lower cranial nerve dysfunction very often improves, often over a period of months. ${ }^{13}$ Many authors have noted that pain related to syringomyelia may not respond to posterior fossa decompressive surgery, even though the size of the syrinx cavity is reduced. Persistence of the syrinx cavity after posterior fossa decompression also occurs in a small percentage of patients and may be related to undetected or reformed occlusions at the outlet of the fourth ventricle. ${ }^{72}$

Imaging improvement is observed in the form of enlargement of the cisterna magna and reduction in the size of the syrinx cavity. A relationship of the Chiari anomaly to vascular alterations has received relatively little attention, but there is evidence that both arterial ${ }^{54}$ and venous circulation $^{5}$ relate to aspects of outcome. Attempts have been made to systematize the measurement of outcomes of treatment for Chiari anomaly ${ }^{4}$ and assess the impact of decompression surgery on the quality of life. ${ }^{33}$

\section{Surgical Treatment of PSS}

Surgical treatment of syringomyelia was, for many years, limited to shunting of the syrinx cavity into an extraneural compartment, such as the pleural space or the abdominal cavity. High shunt failure rates were observed, ,9,12,37,65 not surprisingly because collapse of the syrinx cavity around the shunt tubing tends to occlude the shunt orifices. MRI and other imaging advances led to a better understanding of the pathology in many patients with PSS. Specific treat- ment with resection of focal scar or arachnoid membranes demonstrated by myelography have been used extensively, with or without duraplasty. ${ }^{40}$ In posttraumatic syringomyelia cases in which persistent bone compression still exists, extradural spinal canal decompression can result in syrinx reduction or resolution. ${ }^{37}$ The presumed mechanism is alleviation of the direct subarachnoid space compression, with restoration of the subarachnoid CSF flow. Shunting remains an unavoidable option for some patients with postinflammatory or postinfectious syringomyelia. When subarachnoid resorption of CSF remains possible, shunting into the subarachnoid space is preferable to pleural or peritoneal shunts. Hida et al. recommend placement of the distal shunt tubing anterior to the dentate ligament. ${ }^{35}$

\section{Outcome of Primary Syringomyelia Surgery}

The results of surgery for PSS depend on the underlying etiology and the methods used for treatment. The goal of reversing neurological deficit and eliminating associated pain also depends on the age of the patient and, probably, the length of time a syrinx cavity has been present. ${ }^{9}$

The management of neuropathic pain encountered by patients who either have or have had syringomyelia continues to be challenging. Response to various modalities differs among patients and it is considered best to try various nonnarcotic medications before resorting to invasive techniques. Gabapentinoids have been most widely used, and their occasional side effects are generally tolerated., 374 Acupuncture has been helpful for some patients. Spinal cord stimulation has been used with success in some patients, but is an invasive procedure and is occasionally associated with implant failure requiring reoperation. ${ }^{75}$

With the availability of better overall care, many patients with syringomyelia are reaching normal life expectancy. Some syringomyelia patients may develop late clinical progression without detectable imaging changes. The belief is that this is analogous to the postpolio syndrome and reflects a superimposition of age-related neuronal loss on underlying syrinx-related cell loss. ${ }^{17}$

\section{Future Directions}

It is acknowledged that our present understanding of the Chiari anomaly and of syringomyelia is incomplete. This is underlined by the exceptions to the general pattern of the disorder, including cases of spontaneous resolution, or recurrence of syringomyelia after a seemingly adequate posterior fossa decompression. Intracranial compliance and pressure relationships offer an important area of study. ${ }^{5}$ Further study of fluid hydrodynamics and pulsatility may also add to our understanding of both the Chiari anomaly and syringomyelia. The relationship of Chiari anomaly to HCTDs and craniocervical instability is in need of clarification, and there would be advantages to a clearer definition of the genetic bases of Chiari anomalies. We are only beginning to examine the cognitive changes seen with Chiari, ${ }^{47}$ specifically a better understanding of cerebellar function. Diffusion tensor imaging and other advanced techniques may offer additional insights into the pathophysiology of the Chiari anomaly and the changes resulting from surgical therapy.,49 Minimally invasive 
decompressive procedures will probably be developed. One hopes that treatment of neuropathic pain, so often a devastating residual even after successful surgery for syringomyelia, will advance and become more effective. A more standardized approach to Chiari research, allowing for comparison of data, is the aim of the NIH-sponsored Common Data Elements project. ${ }^{51}$

\section{References}

1. Abbott D, Brockmeyer D, Neklason DW, Teerlink C, Cannon-Albright LA: Population-based description of familial clustering of Chiari malformation Type I. J Neurosurg 128:460-465, 2018

2. Abeshaus S, Friedman S, Poliachik S, Poliakov A, Shaw D, Ojemann J, et al: Diffusion tensor imaging changes with decompression of Chiari I malformation. Neurosurgery 71:E578, 2012

3. Ahn SH, Park HW, Lee BS, Moon HW, Jang SH, Sakong J, et al: Gabapentin effect on neuropathic pain compared among patients with spinal cord injury and different durations of symptoms. Spine (Phila Pa 1976) 28:341-347, 2003

4. Aliaga L, Hekman KE, Yassari R, Straus D, Luther G, Chen $\mathrm{J}$, et al: A novel scoring system for assessing Chiari malformation type I treatment outcomes. Neurosurgery 70:656665,2012

5. Alperin N, Loftus JR, Bagci AM, Lee SH, Oliu CJ, Shah AH, et al: Magnetic resonance imaging-based measures predictive of short-term surgical outcome in patients with Chiari malformation Type I: a pilot study. J Neurosurg Spine 26:28-38, 2017

6. Arnautovic A, Splavski B, Boop FA, Arnautovic KI: Pediatric and adult Chiari malformation Type I surgical series 1965-2013: a review of demographics, operative treatment, and outcomes. J Neurosurg Pediatr 15:161-177, 2015

7. Ashley-Koch A: Chiari malformation \& hereditary disorders of connective tissue: genetics, diagnosis, epidemiology, presented at the Chiari \& Syringomyelia Foundation Colloquium Proceedings, October 18, 2014 (https://www.csfinfo. org/research/csf-funded-research/csf-research-colloquiumco-morbidities-chiari/chiari-connective-tissue-genetics/) [Accessed August 2, 2019]

8. Barkovich AJ, Wippold FJ, Sherman JL, Citrin CM: Significance of cerebellar tonsillar position on MR. AJNR Am J Neuroradiol 7:795-799, 1986

9. Batzdorf U: Primary spinal syringomyelia. Invited submission from the Joint Section Meeting on Disorders of the Spine and Peripheral Nerves, March 2005. J Neurosurg Spine 3:429-435, 2005

10. Batzdorf U: Treatment of syringomyelia associated with Chiari malformation in syringomyelia, in Tamaki N, Batzdorf U, Nagashima T (eds): Syringomyelia: Current Concepts in Pathogenesis and Management. Tokyo: Springer-Verlag, 2001, pp 121-123

11. Batzdorf U, Benzel EC, Henderson FC Sr: Consensus statement, in Batzdorf U, Benzel EC, Henderson FC Sr (eds): Proceedings of CSF Colloquium 2013: Basilar Impression \& Hypermobility at the Craniocervical Junction. Staten Island, NY: Chiari \& Syringomyelia Foundation, 2013

12. Batzdorf U, Klekamp J, Johnson JP: A critical appraisal of syrinx cavity shunting procedures. J Neurosurg 89:382-388, 1998

13. Batzdorf U, McArthur DL, Bentson JR: Surgical treatment of Chiari malformation with and without syringomyelia: experience with 177 adult patients. J Neurosurg 118:232-242, 2013

14. Bejjani GK: Association of adult Chiari malformation and idiopathic intracranial hypertension more than a coincidence. Med Hypotheses 60:859-863, 2003
15. Bhattacharjee AK, Tamari N, Nagashima T, Ehara K: Intraoperative ultrasonography during foramen magnum decompression for syringomyelia associated with Chiari I malformation, in Tamaki N, Batzdorf U, Nagashima T (eds): Syringomyelia: Current Concepts in Pathogenesis and Management. Tokyo: Springer-Verlag, 2001, pp 90-96

16. Bilston LE, Stoodley MA, Fletcher DF: The influence of the relative timing of arterial and subarachnoid space pulse waves on spinal perivascular cerebrospinal fluid flow as a possible factor in syrinx development. J Neurosurg 112:808-813, 2010

17. Bogdanov EI, Heiss JD, Mendelevich EG: The post-syrinx syndrome: stable central myelopathy and collapsed or absent syrinx. J Neurol 253:707-713, 2006

18. Bollo RJ, Riva-Cambrin J, Brockmeyer MM, Brockmeyer DL: Complex Chiari malformations in children: an analysis of preoperative risk factors for occipitocervical fusion. $\mathbf{J}$ Neurosurg Pediatr 10:134-141, 2012

19. Brockmeyer DL, Spader HS: Complex Chiari I malformations in children: diagnosis and management. Neurosurg Clin N Am 26:555-560, 2015

20. Chai Z, Xue X, Fan H, Sun L, Cai H, Ma Y, et al: Efficacy of posterior fossa decompression with duraplasty for patients with Chiari malformation type I: a systematic review and meta-analysis. World Neurosurg 113:357-365, 365.e1, 2018

21. Chiari H: Über Veränderungen des Kleinhirns, des Pons und der Medulla oblongata in Folge von congenitaler Hydrocephalie des Grosshirns. Denkschr Akad Wiss Wien 63:71-116, 1896

22. Cinalli G, Renier D, Sebag G, Sainte-Rose C, Arnaud E, Pierre-Kahn A: Chronic tonsillar herniation in Crouzon's and Apert's syndromes: the role of premature synostosis of the lambdoid suture. J Neurosurg 83:575-582, 1995

23. Cleland J: Contribution to the study of spina bifida, encephalocele, and anencephalus. J Anat Physiol 17:257-292, 1883

24. Duddy MJ, Williams B: Hindbrain migration after decompression for hindbrain hernia: a quantitative assessment using MRI. Br J Neurosurg 5:141-152, 1991

25. Dyste GN, Menezes AH, VanGilder JC: Symptomatic Chiari malformations. An analysis of presentation, management, and long-term outcome. J Neurosurg 71:159-168, 1989

26. Ellenbogen RG, Armonda RA, Shaw DW, Winn HR: Toward a rational treatment of Chiari I malformation and syringomyelia. Neurosurg Focus 8(3):E6, 2000

27. Fenoy AJ, Menezes AH, Fenoy KA: Craniocervical junction fusions in patients with hindbrain herniation and syringohydromyelia. J Neurosurg Spine 9:1-9, 2008

28. Förander P, Sjåvik K, Solheim O, Riphagen I, Gulati S, Salvesen $\varnothing$, et al: The case for duraplasty in adults undergoing posterior fossa decompression for Chiari I malformation: a systematic review and meta-analysis of observational studies. Clin Neurol Neurosurg 125:58-64, 2014

29. Gambardella G, Caruso G, Caffo M, Germanò A, La Rosa G, Tomasello F: Transverse microincisions of the outer layer of the dura mater combined with foramen magnum decompression as treatment for syringomyelia with Chiari I malformation. Acta Neurochir (Wien) 140:134-139, 1998

30. Gardner WJ, Angel J: The mechanism of syringomyelia and its surgical correction. Clin Neurosurg 6:131-140, 1958

31. Goel A, Shah A: Reversal of longstanding musculoskeletal changes in basilar invagination after surgical decompression and stabilization. J Neurosurg Spine 10:220-227, 2009

32. Gowers WR: A Manual of Disease of the Nervous System. London: J \& A Churchill, 1899

33. Greenberg JK, Yarbrough CK, Radmanesh A, Godzik J, Yu M, Jeffe DB, et al: The Chiari Severity Index: a preoperative grading system for Chiari malformation type 1 . Neurosurgery 76:279-285, 2015

34. Heiss JD, Snyder K, Peterson MM, Patronas NJ, Butman JA, 
Smith RK, et al: Pathophysiology of primary spinal syringomyelia. J Neurosurg Spine 17:367-380, 2012

35. Hida K, Iwasaki Y, Koyanagi I, Sawamura Y, Abe H: Surgical indication and results of foramen magnum decompression versus syringosubarachnoid shunting for syringomyelia associated with Chiari I malformation. Neurosurgery 37:673679,1995

36. Hirai T, Korogi Y, Shigematsu Y, Sugahara T, Takashi M, Ushio Y, et al. Evaluation of syringomyelia with threedimensional constructive interference in a steady state (CISS) sequence. J Magn Res Imaging 11:120-126, 2000

37. Holly LT, Johnson JP, Masciopinto JE, Batzdorf U: Treatment of posttraumatic syringomyelia with extradural decompressive surgery. Neurosurg Focus 8(3):E8, 2000

38. Holly LT, Batzdorf U: Management of cerebellar ptosis following craniovertebral decompression for Chiari I malformation. J Neurosurg 94:21-26, 2001

39. Holly LT, Batzdorf U: Slitlike syrinx cavities: a persistent central canal. J Neurosurg 97 (2 Suppl):161-165, 2002

40. Holly LT, Batzdorf U: Syringomyelia associated with intradural arachnoid cysts. J Neurosurg Spine 5:111-116, 2006

41. Isu T, Sasaki H, Takamura H, Kobayashi N: Foramen magnum decompression with removal of the outer layer of the dura as treatment for syringomyelia occurring with Chiari I malformation. Neurosurgery 33:845-850, 1993

42. James HE, Brant A: Treatment of the Chiari malformation with bone decompression without durotomy in children and young adults. Childs Nerv Syst 18:202-206, 2002

43. Kahn EN, Muraszko KM, Maher CO: Prevalence of Chiari I malformation and syringomyelia. Neurosurg Clin N Am 26:501-507, 2015

44. Kennedy BC, Kelly KM, Phan MQ, Bruce SS, McDowell MM, Anderson RCE, et al: Outcomes after suboccipital decompression without dural opening in children with Chiari malformation Type I. J Neurosurg Pediatr 16:150-158, 2015

45. Klekamp J: Surgical treatment of Chiari I malformationanalysis of intraoperative findings, complications, and outcome for 371 foramen magnum decompressions. Neurosurgery 71:365-380, 2012

46. Klekamp J, Iaconetta G, Samii M: Spontaneous resolution of Chiari I malformation and syringomyelia: case report and review of the literature. Neurosurgery 48:664-667, 2001

47. Klinge PM, Batzdorf U, Henderson FC (eds): 2016 CSF Research Colloquium Proceedings: Proposal of Cognition and Cognitive Function in Chiari Malformation \& CSF Disorders. Staten Island, NY: Chiari \& Syringomyelia Foundation, 2018

48. Koç K, Anik Y, Anik I, Cabuk B, Ceylan S: Chiari 1 malformation with syringomyelia: correlation of phase-contrast cine MR imaging and outcome. Turk Neurosurg 17:183-192, 2007

49. Krishna V, Sammartino F, Yee P, Mikulis D, Walker M, Elias $\mathrm{G}$, et al: Diffusion tensor imaging assessment of microstructural brainstem integrity in Chiari malformation Type I. J Neurosurg 125:1112-1119, 2016

50. Leon TJ, Kuhn EN, Arynchyna AA, Smith BP, Tubbs RS, Johnston JM, et al: Patients with "benign" Chiari I malformations require surgical decompression at a low rate. J Neurosurg Pediatr 23:1-9, 2019

51. Luciano MG, Batzdorf U, Kula RW, Rocque BG, Maher CO, Heiss J, et al: Development of Common Data Elements for use in Chiari malformation type I clinical research: an NIH/ NINDS project. Neurosurgery [epub ahead of print], 2019

52. Markunas CA, Soldano K, Dunlap K, Cope H, Asiimwe E, Stajich J, et al: Stratified whole genome linkage analysis of Chiari type I malformation implicates known Klippel-Feil syndrome genes as putative disease candidates. PLoS One 8:e61521, 2013
53. Meadows J, Kraut M, Guarnieri M, Haroun RI, Carson BS: Asymptomatic Chiari Type I malformations identified on magnetic resonance imaging. J Neurosurg 92:920-926, 2000

54. Menezes AH: Current opinions for treatment of symptomatic hindbrain herniation or Chiari type I malformation. World Neurosurg 75:226-228, 2011

55. Milhorat TH, Bolognese PA, Nishikawa M, Francomano CA, McDonnell NB, Roonprapunt C, et al: Association of Chiari malformation type I and tethered cord syndrome: preliminary results of sectioning filum terminale. Surg Neurol 72:20-35, 2009

56. Milhorat TH, Bolognese PA, Nishikawa M, McDonnell NB, Francomano CA: Syndrome of occipitoatlantoaxial hypermobility, cranial settling, and Chiari malformation type I in patients with hereditary disorders of connective tissue. J Neurosurg Spine 7:601-609, 2007

57. Milhorat TH, Capocelli AL Jr, Anzil AP, Kotzen RM, Milhorat RH: Pathological basis of spinal cord cavitation in syringomyelia: analysis of 105 autopsy cases. J Neurosurg 82:802-812, 1995

58. Milhorat TH, Chou MW, Trinidad EM, Kula RW, Mandell M, Wolpert C, et al: Chiari I malformation redefined: clinical and radiographic findings for 364 symptomatic patients. Neurosurgery 44:1005-1017, 1999

59. Oldfield EH, Muraszko K, Shawker TH, Patronas NJ: Pathophysiology of syringomyelia associated with Chiari I malformation of the cerebellar tonsils. Implications for diagnosis and treatment. J Neurosurg 80:3-15, 1994

60. Paré LS, Batzdorf U: Syringomyelia persistence after Chiari decompression as a result of pseudomeningocele formation: implications for syrinx pathogenesis: report of three cases. Neurosurgery 43:945-948, 1998

61. Penfield W, Coburn DF: Arnold-Chiari malformation and its operative treatment. Arch Neurol Psychiatry 40:328-336, 1938

62. Schmidek HH: Neurologic and neurosurgical sequelae of Paget's disease of bone. Clin Orthop Relat Res (127):70-77, 1977

63. Schwalbe E, Gredig M: Über Entwicklungsstörungen des Kleinhirns, Hirnstamms und Halsmarks bei Spina bifida: Arnold'sche und Chiari'sche Missbildung. Beitr Pathol Anat 40:132-194, 1907

64. Sgouros S, Kountouri M, Natarajan K: Posterior fossa volume in children with Chiari malformation Type I. J Neurosurg 105 (2 Suppl):101-106, 2006

65. Sgouros S, Williams B: A critical appraisal of drainage in syringomyelia. J Neurosurg 82:1-10, 1995

66. Smith BW, Strahle J, Bapuraj JR, Muraszko KM, Garton HJ, Maher CO: Distribution of cerebellar tonsil position: implications for understanding Chiari malformation. J Neurosurg 119:812-819, 2013

67. Stoodley MA, Brown SA, Brown CJ, Jones NR: Arterial pulsation-dependent perivascular cerebrospinal fluid flow into the central canal in the sheep spinal cord. J Neurosurg 86:686-693, 1997

68. Strahle J, Muraszko KM, Kapurch J, Bapuraj JR, Garton HJ, Maher CO: Chiari malformation Type I and syrinx in children undergoing magnetic resonance imaging. J Neurosurg Pediatr 8:205-213, 2011

69. Tubbs RS, Beckman J, Naftel RP, Chern JJ, Wellons JC III, Rozzelle CJ, et al: Institutional experience with 500 cases of surgically treated pediatric Chiari malformation Type I. J Neurosurg Pediatr 7:248-256, 2011

70. Tubbs RS, Elton S, Grabb P, Dockery SE, Bartolucci AA, Oakes WJ: Analysis of the posterior fossa in children with the Chiari 0 malformation. Neurosurgery 48:1050-1055, 2001

71. Tubbs RS, Iskandar BJ, Bartolucci AA, Oakes WJ: A critical 
analysis of the Chiari 1.5 malformation. J Neurosurg 101 (2 Suppl):179-183, 2004

72. Tubbs RS, Webb DB, Oakes WJ: Persistent syringomyelia following pediatric Chiari I decompression: radiological and surgical findings. J Neurosurg 100 (5 Suppl Pediatrics):460-464, 2004

73. Udani V, Holly LT, Chow D, Batzdorf U: Posterior fossa reconstruction using titanium plate for the treatment of cerebellar ptosis after decompression for Chiari malformation. World Neurosurg 81:836-841, 2014

74. Vranken JH, Dijkgraaf MG, Kruis MR, van der Vegt MH, Hollmann MW, Heesen M: Pregabalin in patients with central neuropathic pain: a randomized, double-blind, placebocontrolled trial of a flexible-dose regimen. Pain 136:150-157, 2008

75. Williams KA, Gonzalez-Fernandez M, Hamzehzadeh S, Wilkinson I, Erdek MA, Plunkett A, et al: A multi-center analysis evaluating factors associated with spinal cord stimulation outcome in chronic pain patients. Pain Med 12:11421153,2011

76. Yasui K, Hashizume Y, Yoshida M, Kameyama T, Sobue G: Age-related morphologic changes of the central canal of the human spinal cord. Acta Neuropathol 97:253-259, 1999
77. Zolty P, Sanders MH, Pollack IF: Chiari malformation and sleep-disordered breathing: a review of diagnostic and management issues. Sleep 23:637-643, 2000

\section{Disclosures}

The authors report no conflict of interest concerning the materials or methods used in this study or the findings specified in this paper.

\section{Author Contributions}

Conception and design: both authors. Acquisition of data: both authors. Analysis and interpretation of data: both authors. Drafting the article: both authors. Critically revising the article: both authors. Reviewed submitted version of manuscript: both authors. Approved the final version of the manuscript on behalf of both authors: Holly.

\section{Correspondence}

Langston T. Holly: David Geffen UCLA School of Medicine, Los Angeles, CA.1holly@mednet.ucla.edu. 